where he obtained a second class in the Natural Science Tripos in 1912. In 1913 he joined the Imperial College of Science and Technology, London, where he was a contemporary of S. Sugden and C. K. Ingold, and started research work under J. F. (later Sir Jocelyn) Thorpe. He was naturalized in 1916 and served in the anti-gas service during the First World War, being a member of the British Gas Mission to the United States in 1918. He was mentioned in dispatches in 1917. At the end of the War he rejoined Thorpe at the Imperial College. He received the D.Sc. in 1922 , became lecturer in organic chemistry in 1925 and assistant professor in 1934. In 1942 he was appointed professor of chemistry at the Chester Beatty Institute, a post which he held until his death. He was elected a Fellow of the Royal Society in 1943.

Kon's scientific career falls into three parts. The first, up to about 1932, was taken up with the study of tautomerism, particularly the classical work on the migration of the double bond in unsaturated chains. Conspicuous in this period was his work on the glutaconic acids. In the next decade he worked most effectively in the steroid and triterpene groups. $\mathrm{He}$ synthesized the key dehydrogenation product of the steroids, 'Diels' hydrocarbon', and later made important contributions to triterpene chemistry. The final phase came after his appointment to the Chester Beatty Institute, where he was concerned with new types of chemical carcinogens, including aminostilbenes, 'nitrogen mustards', epoxides and other biological alkylating agents. This work shows promise of throwing light on the mechanism of carcinogenesis and mutagenesis. Throughout his career Kon was a most gifted experimentalist, with an assured and masterly technique.

$\mathrm{He}$ was a man of unusually wide tastes and accomplishments; an excellent linguist, an admirable golfer and a lover of fine furniture. But he will be best remembered for his entirely lovable personality which embodied modesty, humour, kindliness and great generosity.

R. P. Linstead

\section{Dr. John S. Paraskevopoulos}

Dr. J. S. Paraskevopoulos, astronomer in charge of the Boyden station of the Harvard Observatory at Bloemfontein, died after a short illness on March 15 last at the age of sixty-one. He will be specially remembered for his work in superintending the taking of photographs of the southern skies, which enabled the Harvard astronomers to study the whole of the sidereal universe and not merely that part which appeared above the local horizon.

"Paras", as he was often called, studied astronomy in his native Greece and, for a short time, worked at the National Observatory at Athens. He saw military service in the Balkan Wars and the First World War, which prevented him proceeding abroad with a scholarship he had won in 1912. In 1919, however, he went to Yerkes Observatory of the University of Chicago, where he spent three years. At Columbia. University he met and married Miss Dorothy W. Black, who accompanied him and took part in his future astronomical work. The Harvard southern station had been erected in the 1890's at a high altitude at Arequipa in Peru, and when "Paras" was sent to take charge of it in 1923 it had been decided to seek another site, as the observing conditions at Arequipa, although excellent for most of the year, were poor from December to March. This left part of the sky poorly observed, and Dr. and Mrs. Paraskevopoulos investigated other sites in Peru and northern Chile. Reports from South Africa ultimately led to the selection of a site at Mazelspoort, about fourteen miles from Bloemfontein, at an altitude of $4,500 \mathrm{ft}$., and this site has proved an excellent one. About the middle of 1927 the first instruments arrived in South Africa, and since then "Paras" was actively engaged in procuring photographs for the Harvard Programme.

In all, ten telescopes were erected at Mazelspoort and have been continuously employed by some half a dozen assistants. The instruments included a 60-in. reflector, the 24-in. Bruce doublet and smaller instruments down to 3 -in. and even $1 \frac{1}{2}$-in. telescopes used as patrol cameras. The work covered most fields of practical astrophysies-nebular surveys, proper motions, photometry, variable stars and spectroscopy. Only a few months ago, a powerful BakerSchmidt reflector was added to the equipment. The number of plates taken in a month sometimes exceeded a thousand.

The time of Dr. Paraskevopoulos was mostly taken up in practical work, and he had little time for personal research. He was specially interested in nebulx and clusters, and as president of the Astronomical Society of South Africa gave his presidential address in 1938 on "The Transparency of Space and Absorbing Material". He naturally took great interest in special occasions such as the total solar eclipse of 1940 and the appearance of bright comets. $\mathrm{He}$ will be much missed by his Harvard colleagues.

Paraskevopoulos retained his Greek nationality, and during the War he and his wife were active in work for assisting Greek refugees in South Africa. His astronomical work was recognized by his election as a member of the Greek Academy of Science.

\section{NEWS and VIEWS}

\section{Festival of Britain}

"ONE hundred years ago Queen Victoria opened the Great Exhibition in Hyde Park. Its creators were far-sighted men who looked forward to a world in which the advances of art and science would uplift civilization to enduring peace and prosperity." With these words, H.M. the King began his address from the steps of St. Paul's Cathedral, when on May 3 he formally declared open the Festival of Britain. $\mathrm{H}_{\ominus}$ referred to the many parallel festivals up and down the country as a visible sign of national achievement and confidence, and he remarked : "Many of these activities and displays will be of lasting value. They will maintain the prestige of our arts and industries abroad by proof of our world-renowned skill in design and craftsmanship; and they will also show how vital a part is played in industry by scientific imagination and research." Another aspect of the past hundred years was stressed by the Archbishop of Canterbury in his address at the ceremony of dedication which preceded the King's speech. He said: "The greatest creation of our nation has been a way of life, a tradition of how men and women and children may live together in the freedom of mutual respect and trust, free to be themselves, free to be generous to others."

So the Festival of Britain has opened. Many eminent men of science have given much thought and time to the scientific displays, and reference was made to this by the Lord President of the Council 